\title{
Culturas Juvenis, culturas digitais e Ensino Médio: quando o diálogo é necessário
}

\author{
Las culturas juveniles, culturas digitales y ensino secundario: Cuándo es \\ necesario el diálogo
}
The Young culture, the digital cultures and the secundary school: when the dialogue is necessary

Dra. Sueli Salva ${ }^{1}$

\begin{abstract}
Resumo
Este artigo tem como objetivo refletir acerca do uso das tecnologias digitais no contexto escolar de ensino médio a partir da compreensão dos professores. Apresenta análises da pesquisa "Mídias e Juventude: aspectos educativos e culturais em (des)encontro". A produção dos dados foi realizada no Brasil, na cidade de Santa Maria, em algumas escolas públicas de ensino médio e na Itália em algumas escolas Secundárias de Segundo Grau. Autores como Gil e Micheli (2011), Barbero (2008), Belonni (2013) se constituem como referencial teórico que busca dialogar com as políticas públicas para o ensino médio no Brasil. Foi possível perceber que apesar dos documentos legais preverem a utilização das tecnologias digitais nos contextos escolares, seu uso ainda é restrito em ambos os países em decorrência, da deficiência na formação dos professores, da estrutura rígida da instituição escolar, das frágeis condições estruturais das escolas, falta de compreensão acerca dos aspectos culturais que envolve a vida juvenil, da pouca reflexão acerca da mudança na relação com o saber, provocada pelas tecnologias digitais cujo tema ainda não foi suficientemente explorado.
\end{abstract}

Palavras-Chave: ensino médio, políticas públicas, relação com o saber, tecnologias digitais, vida juvenil.

\section{Resumen}

Este artículo tiene como objetivo reflexionar sobre el uso de las tecnologías digitales en el contexto educativo de la escuela secundaria de la comprensión del professorado. Se presenta el análisis de la investigación "Medios de comunicación y Jóvenes: Los aspectos educativos y culturales en el encuentro". La producción de los datos se llevó a cabo en Brasil en la ciudad de Santa María, en algunas escuelas secundarias públicas en Italia y en algunas escuelas secundarias de secundo grado. Autores como Gil y Micheli (2011), Barbero (2008), Belonni (2013) constituyen un marco teórico que busca informar a la política pública para la escuela secundaria en Brasil. Se pudo observar que a pesar de los documentos legales prevén el uso de las tecnologías digitales en el contexto escolar, su uso sigue siendo limitado en ambos países como resultado de la deficiencia en la formación de docentes, la estructura rígida de la escuela, las condiciones estructurales frágiles de las escuelas, la falta de comprensión de los aspectos culturales relacionados con la vida juvenil, sin pensar en el cambio en la relación con el saber, provocada por las tecnologías digitales cuyo objeto no ha sido suficientemente explorado.

Palabras claves: escuela secundaria, políticas públicas, relación con el saber, tecnologías digitales, vida juvenil.

\section{Abstract}

\footnotetext{
${ }^{1}$ Doutora em Educação; Universidade Federal de Santa Maria - UFSM; Santa Maria, Rio Grande do Sul, Brasil; susalvaa@gmail.com
} 

e-ISSN 2016/Atual: 2525-7870 | e-ISSN 2015/2016: 2447-018X

This article has the objetctive to reflect about the use off the digital Technologies in the scholar context of high school, from the understanding of the theachers. Presentes reviews from the research "Mídias e juventude: aspectos educativos e culturas em (des)encontro". The production of the dates was realizaed in Brasil, on the Santa Maria Cit, in the high public schools, and in the Italy in the secondary schools. Some authors like Gil e Micheli (2011), Barbero (2008), Belonni (2013) was constituted like a theoric reference who wants the dialogue with the public politics to the Brazilian high school. Was possible to perceive that although the legal documents anticipate the use off the digital thecnologies on the scholar contexts, there use still are restricted in above the countries as a result fro the Deficiency on the teachers formation, fron the rigid estructure off the scholar institution, from the fragiles estructures of the schools, the lack of understanding of the cultural aspects who envolve the Young lives, the few reflections although the changes off the relation with the knowledge, provoked by the digitals thecnologies whose theme wasn't explored enough.

Palavras-Chave: High school, public policies, relationship with knowledge, digital technologies, youth life.

\section{Introdução}

Este artigo se propõe a discutir a temática relativa à formação educativa dos jovens do ensino médio, buscando aprofundar aspectos relativos a cultura juvenil vinculada as novas tecnologias da informação e da comunicação (TICs) especialmente as tecnologias digitais e seu uso a escola. O ponto de partida são as propostas relativas ao uso das tecnologias apontadas nas políticas públicas para o ensino médio e a partir delas verificar como elas são colocadas em prática no contexto escolar brasileiro e italiano. A ideia da pesquisa surge quando se passa a observar as dificuldades ainda encontradas no contexto escolar brasileiro para estabelecer um diálogo entre a cultura escolar e culturas juvenis, dificuldade que se adensa a partir da massificação da educação e ingresso de jovens de outras classes na escola, mas principalmente pela estreita relação que os jovens constroem com as tecnologias digitais as quais a escola ainda mantém certa distância.

Entende-se que as tecnologias digitais são responsáveis por provocar mudanças profundas no que diz respeito ao sujeito e sua capacidade cognitiva relativamente, a memória, imaginação e percepção afetando a relação com o saber, conforme argumenta Lèvy (2011), o que pode de algum modo, aumentar ainda mais os problemas de distorção idade-série e do abandono escolar ainda tão evidente no Brasil. Argumenta o autor que esses artefatos, se bem utilizados, podem converter-se em estratégias para potencializar e estreitar a relação entre culturas escolar e cultura juvenil favorecendo uma relação positiva com o saber, que significa segundo Charlot (2013) estabelecer um sentido para a aprendizagem e de alguma forma conecta-la ao prazer.

\section{Aspectos Metodológicos}

Utilizou-se a metodologia qualitativa de caráter etnográfico e comparativa definida a partir do objeto de estudo, do discurso e da agenda (REBUGHINI, 2005). Em relação ao 

e-ISSN 2016/Atual: 2525-7870 | e-ISSN 2015/2016: 2447-018X

objeto direcionou-se o foco sobre as culturas juvenis produzidas a partir da interferência das tecnologias digitais e sua influência no contexto educativo escolar. Os dados empíricos utilizados para essa análise foram produzidos em duas escolas públicas do Ensino Médio de Santa Maria/ RS/Brasil e duas escolas Secundárias de Segundo Grau de Milão/Itália; do ponto de vista do discurso aprofundou-se os aspectos teóricos que forneceram elementos para análise comparativa entre os contextos brasileiros e italianos sobre o tema. A agenda desse estudo compromete-se a interferir na formação dos professores, desenvolver aspectos metodológicos relativos à pesquisa sobre culturas juvenis, tecnologias e educação, impulsionar a pesquisa sobre o tema nos Programa de Pós-Graduação em Educação, bem como na implementação das políticas públicas propostas para o Ensino Médio no Brasil. Nos contextos escolares italianos realizou-se observação e entrevista com professores.

\section{As políticas públicas de inclusão digital para o Ensino Médio no Brasil e Itália}

$\mathrm{Na}$ última década no Brasil, foram implementadas algumas políticas que visam qualificar o ensino médio: As Diretrizes Curriculares Nacionais para o Ensino Médio (DCNEM), o Programa Ensino Médio Inovador (ProEMI), o Pacto Nacional pelo Fortalecimento do Ensino Médio e no Rio grande do Sul (RS) a implementação da "Proposta Pedagógica para o Ensino Médio Politécnico e Educação Profissional Integrada ao Ensino Médio.

As DCNEM, aprovadas pelo conselho nacional de educação em maio de 2011, visam definir uma identidade para o ensino médio. Uma das recomendações das DCNEM que consta no Artigo 16 é referente ao projeto político pedagógico que deve considerar:

VIII - utilização de diferentes mídias como processo de dinamização dos ambientes de aprendizagem e construção de novos saberes.

XX - produção de mídias nas escolas a partir da promoção de atividades que favoreçam as habilidades de leitura e análise do papel cultural, político e econômico dos meios de comunicação na sociedade (BRASIL. DCNEM, 2012, p. 07).

Outra política é o ProEMI do Ministério da Educação, cujo texto aprovado através do Parecer CNE/CP nº 11/2009, pelo Ministério da Educação e readequado em 2013 e em 2014, estabelece como objetivo "apoiar e fortalecer o desenvolvimento de propostas curriculares inovadoras nas escolas de Ensino Médio, [...] com a inserção de atividades que tornem o currículo mais dinâmico, atendendo as expectativas dos estudantes e demandas da sociedade contemporânea" (BRASIL, 2009, p. 3). E por fim o Pacto Nacional pelo Fortalecimento do Ensino Médio (Portaria n 1.140 de 22 de novembro de 2013 - Diário Oficial da União). 
Ainda a política mencionada implementada no Rio grande do Sul (RS) é a "Proposta Pedagógica para o Ensino Médio Politécnico e Educação Profissional Integrada ao Ensino Médio - 2011-2014” (AZEVEDO; REIS, 2013), que propõe: A construção de uma nova proposta político pedagógica em que o ensino das áreas de conhecimento dialogue com o mundo do trabalho, que interaja com as novas tecnologias (SEDUC, p. 4).

As recomendações das DCNEM, do ProEMI, o Pacto pela Valorização do Ensino Médio e a reforma curricular do Ensino Médio no RS, articulam-se quando enfatizam e propõem uma educação direcionada às necessidades da sociedade contemporânea e quando sinalizam a emergência em pensar um currículo que inclua as mídias digitais e processos comunicativos dos jovens estudantes, incluído suas culturas e necessidades para construção de seus percursos de vida.

No Brasil foi criado em 1997, o Programa Nacional de Informática na Educação (ProInfo), ligado a Secretaria da Educação a Distância (SeeD) e Programa Um Computador por Aluno (PROUCA) instituído pela Lei $\mathrm{n}^{\circ}$ 12.249, de 14 de junho de 2010, com o objetivo de promover a inclusão digital pedagógica e o desenvolvimento do processo de ensino e aprendizagem de alunos e professores (BRASIL, 2010).

Na Itália a ECDL (European Computer Driving License), através da fundação com o mesmo nome, autoriza e apoia o desenvolvimento continuo de competências em tecnologias digitais. Os programas mais importantes implementados na Itália que visam a integração das tecnologias no sistema escolar. Il Programma di Sviluppo delle Tecnologie Didattiche (PSTD)-(Programa de desenvolvimento das tecnologias didáticas), Minestero Della Pubblica Instruzione (Ministério da Educação Pública), que tem como objetivo educar os estudantes para o usos da multimídia e da comunicação; melhorar a eficácia do ensino e aprendizagem das disciplinas; qualificar a formação docente. Esse programa articula-se a outros dois: "Unità operativa per docenti" (unidade operacional para os docentes e "Multimedialità in classe” e (multimídia na aula).

Outro programa iniciado em 2002 é "Il Piano di e-government del MIUR² ed il Piano Nazionale di Formazione degli Insegnanti sull'ICT' (Plano de Governo do Ministério da Educação da Universidade e da Pesquisa e Plano Nacional de Formação dos professores sobre as TICs). Em 2008 é colocado em prática o "Piano Nazionale Scuola Digitale" (Plano Nacional Escola Digital) que se inspira em um plano da União Europeia até o ano de 2020,

\footnotetext{
${ }^{2}$ Ministero dell'Istruzione, dell’Università e della Richerca (Ministério da Educação da Universidade e da Pesquisa).
} 
com objetivo de fazer a "difusão sempre mais capilar das tecnologias digitais no interior da realidade escolar" (ARRUFAT; MASINI, 2012, p. 264).

Tanto no Brasil como na Itália percebemos que há uma preocupação por parte dos governos para a qualificação do uso das tecnologias, porém esse é apenas o início de um processo que já anuncia muitas mudanças. As mudanças provocadas pelas mídias digitais sinalizam desafios para a educação relativos à: formação dos professores; a construção de um novo olhar para os jovens que possibilite respeitá-los na sua condição de aluno, humana, relacional e afetiva, compreendendo aspectos culturais que envolvem a vida dos jovens; estratégias metodológicas que incluam as mídias digitais; infraestrutura do sinal de internet e computadores com programas atualizados que possibilitem a realização de um trabalho de qualidade (no caso do contexto brasileiro) e por último compreender as mudanças ocasionadas pela massificação da tecnologia digital.

\section{A escola de Ensino Médio, culturas e as tecnologias digitais: desafios, limites e possibilidades}

O fio desta história é a convicção de que temos que integrar essas máquinas maravilhosas à escola, em todos os seus níveis e modalidades; convicção que foi se tornando mais forte à medida que as novas e novíssimas tecnologias de informação e comunicação (TICs) vão se tornando cada vez mais presentes, mais indispensáveis, em todas as esferas da vida social (BELLONI, 2012, p. 32).

$\mathrm{O}$ argumento posto pela autora citada, pesquisadora da área, sinaliza a necessidade de pactuar uma aliança entre as tecnologias digitais e a escola. As tecnologias digitais hoje interferem na cultura, mais ainda nas culturas juvenis. As tecnologias provocaram intensas mudanças nos contextos sociais, culturais e, como sinalizado por Lèvy (2011) até mesmo nas formas de organização do pensamento e relação com o saber. Mesmo com essa intensa mudança nos contextos sociais e culturais impulsionados pelas novas e novíssimas tecnologias a escola insiste em organizar-se inspirada na estrutura a qual foi criada, cujo tempo e quantidade de estudantes era muito menor e as mudanças ocorriam mais lentamente, mais ligadas ao ciclo da natureza. A escolarização de massa, adensada pela velocidade que ocorrem as transformações do conhecimento, as inovações provocadas pelas tecnologias digitais no tempo contemporâneo, avolumam os problemas educacionais e cria novos.

O enfrentamento desses problemas necessita ocorrer no âmbito da política, do epistemológico e do pedagógico. No âmbito da política porque dela depende o direcionamento das ações governamentais e investimento econômico, no âmbito epistemológico, pois é esse campo que orienta os paradigmas, princípios e fundamentos da 
educação e no âmbito do pedagógico que orienta as ações cotidianas no interior das escolas. Esses três contextos estão intimamente conectados. A eficiência das práticas pedagógicas depende dos três e em grande parte, da política de formação de professores que vise a construção de um entendimento sobre as culturas juvenis. De acordo com Dayrell (2008) as culturas juvenis são práticas sociais, que possuem significados próprios e que são compartilhados com os pares, como forma de pertencimento a um grupo. As culturas juvenis possuem uma linguagem própria, cujo sentido não é dado, mas construído na interação com os grupos. Essa construção permite em cada grupo as culturas tenham significados próprios e desse modo, tem uma de suas características a diversidade. Para compreender esse aspecto, é fundamental um processo de escuta atenta aos jovens e os aspectos culturais que dão sentido as suas vidas, hoje, sensivelmente influenciados pelas novas tecnologias.

Em relação ao conhecimento acerca das novas tecnologias, Belloni (2012), argumenta que é muito mais difícil a tarefa de integrar as novas tecnologias à formação de professores. Essa dificuldade decorre principalmente pela deficiência na formação inicial; pelos computadores sem qualidades ainda presentes na escola e principalmente pela estrutura da escola. Instituição conservadora por natureza, [ ... ], a escola, em todos os seus níveis tende a rejeitar a inovação, especialmente a inovação técnica (BELLONI, 2012, p. 54).

Esse paradoxo entre a estrutura conservadora da escola e as mudanças provocadas pelas tecnologias são percebidas pelos professores entrevistados, tanto no contexto brasileiro como italiano.

"Eu tenho pensado em vários fatores, mas talvez isso tenha relação com a mudança que tivemos na sociedade. A estrutura da escola não mudou, mas as tecnologias provocaram uma mudança, isso faz com que os jovens se sintam afastados porque a escola não consegue aceitar, a escola não acompanha, também nós professores não conseguimos acompanhar" (professora brasileira 2).

"É fascinante trabalhar com os jovens, eles sempre me trazem novidades. A escola é a mesma, tem a mesma estrutura, mas eles, eles nos desafiam, nos trazem coisas novas, fico muito satisfeita com essa relação, no fim recebo e aprendo muito com eles" (professora italiana 4).

A rigidez na estrutura escolar se contrapõe a necessidade dos estudantes que cada vez mais exigem inovação relativa a metodologias de ensino. Eles não só anunciam a novidade na relação com os professores como anunciam para a própria instituição. Segundo Lèvy (2011) os indivíduos suportam cada vez menos seguir estruturas rígidas e que não atendem as 
necessidades dos reais percursos de vida. A invasão da tecnologia provoca mudanças profundas nos processos sociais e também nos individuais, subjetivos.

Os jovens hoje tem uma relação íntima e estruturalmente mediada pela e com a tecnologia e segundo Barbero (2008, p. 22) "é desse lugar que nos olham e ouvem". A população juvenil é notadamente o segmento social mais incluso no mundo digital. Todavia, exatamente por isso, dimensões mais profundas de desigualdade digital exercem efeito sobre essa população. Há diferenças, em relação à capacidade de desfrutar do uso da internet entre jovens de diversas classes sociais, mas também são visíveis as diferenças entre as diferentes gerações provocando uma "subutilização" desses novos instrumentos para a formação e crescimento cultural e participação política e social (GIL, MICHELI, 2011, p. 48).

"As tecnologias não são muito utilizadas na escola, quando um professor tenta usar, muitos estudantes pensam que a aula é uma brincadeira. Daí o professor, volta com uma metodologia tradicional" (Lu - estudante brasileiro).

"Eu quero inventar alguma coisa, eu não sei, talvez fazer um vídeo, inventar um jogo. No entanto, a tecnologia na aula é usada para fazer aula com o Power Point, pra mostrar algumas imagens, pra entender melhor a aula"(CA - estudante italiano).

A "subutilização" da tecnologia está muito mais presente nas escolas brasileiras, justamente pelo efeito da desigualdade digital entre os países desenvolvidos e países em desenvolvimento. Percebe-se que o processo formativo para os professores utilizarem a tecnologia digital na escola é fundamental, além disso, esse processo exige reflexão por parte do corpo docente e discente em relação ao uso. A escola tem uma intencionalidade e o uso da tecnologia não pode ser descomprometido, alheio a essa intencionalidade. Ou seja, existe diferença entre utilizar a tecnologia como forma de lazer, estabelecer relações, formas de contato, obter informações e utilizar a tecnologia para fomentar o processo criativo dos estudantes.

\section{Conclusão}

Um primeiro aspecto que podemos destacar é a intimidade que grande parte dos jovens estudantes tem com as novíssimas tecnologias, ou seja, com as tecnologias digitais que contem características como portabilidade, intermedialidade, conectividade. Essa mudança precisa ser enfrentada para que reverta em benefício dos jovens. Enfrenta-la significa assumir a necessidade de formação de professores de forma a instrumentaliza-los para que potencializem seu uso no contexto escolar. A formação específica pode fazer diferença. Existem diferenças significativas em relação à estrutura das tecnologias disponíveis nos dois 

e-ISSN 2016/Atual: 2525-7870 | e-ISSN 2015/2016: 2447-018X

contextos, especialmente, no que se refere ao sinal de internet e aos computadores. Em relação à formação continuada dos professores há uma preocupação no contexto brasileiro que se evidencia através das políticas públicas de formação de professores em geral, mas especificamente em relação ao uso das tecnologias ainda há deficiência apesar de todas as políticas evidenciarem essa importância. Percebe-se que no contexto italiano em algumas disciplinas as tecnologias parecem estar integradas ao contexto das salas de aula, enquanto que no Brasil ainda há uma fragilidade, uma dificuldade para fazer essa integração. Esse uso no, entanto, não potencializa a possibilidade de criação, o uso é ainda limitado uma vez que não se permite que os estudantes criem mediados pela tecnologia.

\section{Referências}

ARRUFAT, María Jesús Gallego; MASINI, Stefano. Politica educativa e integración de las TIC en el Sistema Educativo: la situación italiana dentro del escenario internacional. In. Revista del currículum y formación del profesorado. Vol. 16, no 3. Sept/dicembre 2012, p.245 $-284$.

BARBERO, José Martín. A mudança na percepção da juventude: sociabilidade, tecnicidade e subjetividade entre os jovens. In. BORELLI, Silvia H. S. ; FILHO, João Freire. Culturas Juvenis no Século XXI. São Paulo: EDUC, 2008.

BELLONI, Maria Luiza. Mídia-educação: contextos, histórias e interrogações. In. FANTIN, Mônica; RIVOLTELLA, Pier Cesare (org). Cultura Digital e Escola - pesquisa e formação de professores. Campinas: Papirus, 2012.

BRASIL. Parecer $n^{\circ} 5$ de 2011 - Diretrizes Curriculares Nacionais Para o Ensino Médio. Ministério da Educação, Conselho da Educação Básica: Brasília, 2011.

. Resolução no2 de 30 de janeiro de 2012. Diretrizes Curriculares Nacionais para o Ensino Médio. Brasília, 2012.

. Programa Ensino Médio Inovador. Ministério da Educação. Brasília, 2009.

. Programa Um Computador Por Aluno (ProUCA). Lei no 12.249, de 14 de junho de 2010. MEC/Brasília, 2010.

. Programa Ensino Médio Inovador. Ministério da Educação. Brasília, 2013.

. Portaria nº 971, de 9 de outubro de 2009. Ministério da Educação. Brasília, 2009.

Portaria $\mathrm{n}^{\mathrm{o}}$ 1.140, de 22 de novembro de 2013. Brasília, 2013.

CHARLOT, Bernard. Da relação com o saber às Praticas educativas: São Paulo: Cortez, 2013. 

e-ISSN 2016/Atual: 2525-7870 | e-ISSN 2015/2016: 2447-018X

DAYRELL, Juarez. Escola e culturas juvenis. In: FREITAS, M. V.; PAPA, F. de C. (Orgs.). Políticas Públicas: a juventude em pauta. $2^{\mathrm{a}}$ Ed. Ação Educativa. Fundação Friedrich Ebert. São Paulo: Cortez, 2008.

LEVY, Pierre. Cybercultura: gli usi sociali delle nuove tecnologie. Milano: Feltrinelli, 2011.

MELUCCI, Alberto. A invenção do Presente - Movimentos Sociais Nas sociedades Complexas. Petrópolis: Vozes, 2001.

REBUGHINI, Paola. A comparação qualitativa de objetos complexos e os efeitos da reflexividade. In. MELUCCI, Alberto. Por uma Sociologia Reflexiva - Pesquisa qualitativa e Cultura. Petrópolis: Vozes, 2005. 